\title{
Impact response of glass/epoxy laminate interleaved with nanofibrous mats
}

\author{
H. Saghafi ${ }^{a^{*}}$, R. Palazzettia ${ }^{a, b}$ A. Zucchelli ${ }^{a}$ and G. Minak ${ }^{a}$
}

${ }^{a}$ Department of Industrial Engineering (DIN), University of Bologna, viale del Risorgimento 2, 40136, Bologna, Italy ${ }^{b}$ Design, Manufacture and Engineering Management (DMEM) department, University of Strathclyde, Glasgow, UK

\begin{tabular}{|c|c|}
\hline $\begin{array}{l}\text { ARTICLE INFO } \\
\end{array}$ & A B S T RAC T \\
\hline $\begin{array}{l}\text { Article history: } \\
\text { Received March 20, } 2013 \\
\text { Received in Revised form } \\
\text { September, } 14,2013 \\
\text { Accepted } 16 \text { September } 2013 \\
\text { Available online } \\
16 \text { September } 2013 \\
\text { Keywords: } \\
\text { Composite materials }\end{array}$ & $\begin{array}{l}\text { Plain and nanofiber-interleaved glass/epoxy laminates clamped according to ASTM D7136 } \\
\text { tested under impact loading to assess the improvement in impact resistance of composite } \\
\text { laminates that have been interleaved by electrospun polyvinylidene fluoride (PVDF) nanofibers } \\
\text { with two different thicknesses. Composite specimens with stacking sequence [0/90/0/90]S were } \\
\text { impacted at impact energy of 5J. Variation of the impact characteristics such as maximum } \\
\text { contact load, maximum deflection, maximum contact time, absorbed energy are depicted in the } \\
\text { figures. The results showed that PVDF nanofibers are not a good choice for toughening epoxy } \\
\text { and improving impact damage resistance of GFRP. }\end{array}$ \\
\hline
\end{tabular}

Impact loading

Nanofibers

Interleaving

\section{Introduction}

Compared with more traditional materials such as metals, ceramics, and polymers, fiber reinforced composites have several specific features such as high stiffness and strength to weight ratio, excellent corrosion resistance, and ability in providing both mechanical as well as functional properties. The most common failure mode of this high performance laminated material is delamination as a consequence of low velocity impact, and/or cyclic loading during manufacturing or service life. Insufficient fracture toughness and delamination existence has been the main issue affecting the longterm reliability of thermosetting matrix composites. A number of methods to prevent delamination were developed and evaluated over the years. These include matrix-toughening (Ishai, et al., 1978; Verrey et al., 2005), use of braided fabric (Dow \& Dexter, 1997), edge cap reinforcement (Howard et al., 1986), through-thickness stitching (Dransfield et al., 1998; Jain et al., 1998), and etc. Ductile interleaving seems to be one of the recommended methods, in which interleaf layers of toughened materials were inserted into middle plies of the composites. Generally, thermoplastic particles and

* Corresponding author.

E-mail addresses: hamed.saghafi2@unibo.it (H. Saghafi)

C 2013 Growing Science Ltd. All rights reserved.

doi: $10.5267 /$ j.esm.2013.09.002 
films have been used as common toughened layers (Lu et al., 1995, Sohn et al., 2000). However, difficult preparation of particles due to high toughness of thermoplastic and high thickness of films due to high viscosity of thermoplastic have limited their uses in industry. Recently, nanofibers reinforcing was known as a more useful technique instead of particles or films reinforcing to enhance the mechanical properties of composite because of very small diameter.

Dzenis and Reneker (2001) firstly reported the use of nanofibers to reinforce carbon fiber composite laminate, and they found that entangled nanofibers showed improvement in the interlaminar fracture resistance. Akangah et al. (2010) assessed the improvement in impact resistance of composite laminates that have been interleaved by electrospun Nylon-66 nanofabric. Their results showed that the polymer nanofabric interleaving increased the threshold impact force by about $60 \%$, reduced the rate of impact damage growth rate to one-half with impact height and reduced impact damage growth rate from 0.115 to $0.105 \mathrm{~mm}^{2} / \mathrm{N}$ with impact force. Li et al. (2008) compared the mode I fracture toughness $\left(\mathrm{G}_{\mathrm{IC}}\right)$ of two different toughened carbon/epoxy: 1- toughened by polysulfone (PSF) nanofibers 2- toughened by PSF films. Mode I fracture toughness of the nanofibers toughened composite was $140 \%$ and $280 \%$ higher than those of PSF films toughened and untoughened composite due to the uniform distribution of polysulfone spheres. So far, most researches has been concentrated on the effect of interleaved nanofibers on mode I and mode II fracture toughness and there is a very limited work regarding the response of these materials under impact loading. In this study, nanofibers produced by polyvinylidene fluoride (PVDF) are inserted between GFRP layers and impact tests are conducted to evaluate the effect of the nanofibrous mats to the laminate impact response in terms of energy absorbing capability, maximum load and etc.

\section{Experimental Process}

\subsection{Materials}

Unidirectional glass/epoxy prepreg supplied by G. Angeloni Srl is applied to improve its damage resistance by using interleaving. PVDF were sourced from Solvay in the form of powder (Table 1), Dimethylsulfoxide and Acetone are used as the solvent.

Table 1. PVDF properties

\begin{tabular}{ll}
\hline Property & Value \\
\hline Density & $1.75-1.8 \mathrm{~g} / \mathrm{cm}^{3}$ \\
Melting point & $170-175^{\circ} \mathrm{C}$ \\
Transition Temperature $\left(\mathrm{T}_{\mathrm{g}}\right)$ & $-40{ }^{\circ} \mathrm{C}$ \\
\hline
\end{tabular}

\subsection{Electrospinning method}

Electrospinning is a process that utilizes electrostatic force to spin fibers from a polymeric solution. PVDF powder were dissolved in Dimethylsulfoxide/Acetone $(30: 70 \mathrm{v} / \mathrm{v})$ and the resulting solution transferred to a syringe fitted with a fine needle. The needle was maintained at a positive potential of tens of kilovolts and the collector was grounded. By increasing the electric potential between needle and collector, a critical stage was reached when the surface tension of the solution was overcome by the applied electrostatic field, thereby ejecting tiny jets of the solution from the syringe tip. The discharged jet undergoes a whipping action that further elongates the polymer, and the repulsive electrostatic field splits the jet into fine submicron fibers that were collected on a grounded metal collector or drum. The polymer fiber diameter and its alignment depends on the type and concentration of polymer in the solution, applied voltage, flow rate, needle diameter, distance between needle and collector drum, and the type of collector. A schematic picture of electrospinning process is illustrated in Fig. 1 and the SEM image of electrospun fabric is shown in Fig. 2. The fibers diameter ranged from 300 to $700 \mathrm{~nm}$ and lengths of several centimetres. The electrospinning parameters used were: $15 \% \mathrm{w} / \mathrm{V}$ PVDF concentration, $14 \mathrm{kV}$ applied voltage, $15 \mathrm{~cm}$ distance 
between needle and collector, flow rate $0.01 \mathrm{ml} / \mathrm{min}$ per nozzle, and 60 and $90 \mathrm{~min}$ spinning duration for thin and thick nanofiber mats, respectively. By conducting this process with these parameters the thickness of obtained mats is 39 and $64 \pm 6 \mu \mathrm{m}$ for thin and thick mats, respectively.

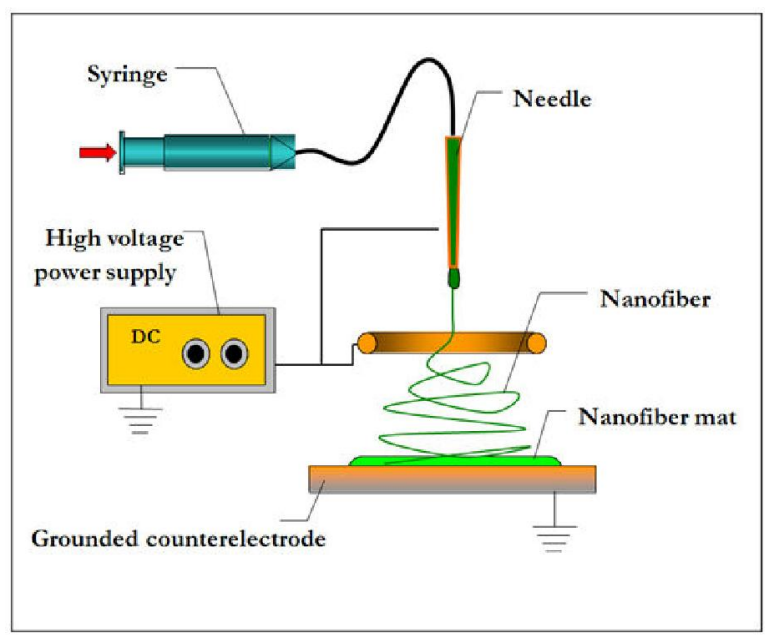

Fig. 1. Electrospinning process (schematic)

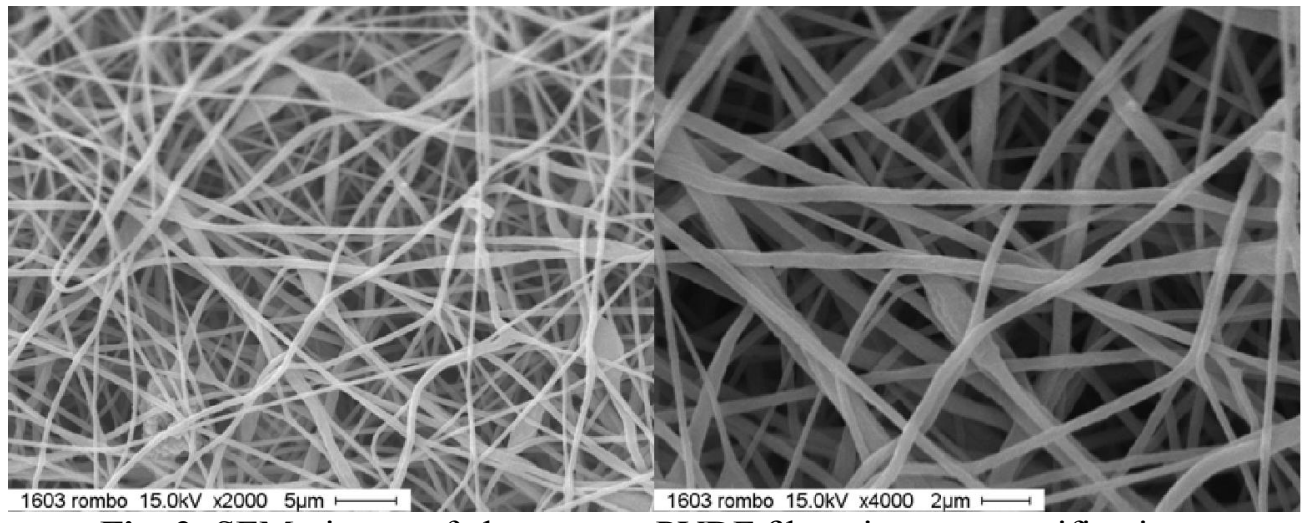

Fig. 2. SEM picture of electrospun PVDF fibers in two magnifications

\subsection{Sample preparation}

Glass fiber/epoxy prepreg was kindly supplied by Metal T.I.G. Company. Nine laminates of $[0 / 90 / 0 / 90]_{S}$ stacking sequence was used for fabricating impact test panels. Interleaved panels were made by placing one layer of polymer nanofabric in between two consecutive prepregs except between middle layers where two $90^{\circ}$-layers are on each other. Then, test panels were cured by using a vacuum bag in an autoclave under $130^{\circ} \mathrm{C}$ and for about 1 hour (according to supplier's suggestion). Specimens were cut from the laminates using a diamond saw into rectangular specimens $150 \mathrm{~mm}$ in length and $100 \mathrm{~mm}$ in width and the thickness of the baseline and interleaved laminates are $2.6 \mathrm{~mm}$.

\subsection{Impact Tests}

Low velocity impact tests were conducted in a drop-weight machine, shown in Fig. 3, equipped with a laser device for determining the position of impactor, a piezoelectric load cell on the tip of the impactor for measuring the contact force during impact. The impactor was a steel spherical ball having a diameter of $12.7 \mathrm{~mm}$. Although, this setup has the potential to cause repeated strikes, but multiple collisions were avoided by means of an electromagnetic braking system. The overall 
impactor mass was $1.22 \mathrm{~kg}$; the drop heights of $41 \mathrm{~cm}$ were chosen, corresponding to a nominal potential energy of $4.9 \mathrm{~J}$. Three tests were performed for each configuration: 1-interleaved specimen (thin laminates) 2- interleaved specimen (thick laminates) 3-plain specimen. The specimen was placed on a rectangular steel base with a 125 by $75 \mathrm{~mm}$ rectangular opening, being correctly positioned thanks to three pins and held by four lever clamps with rubber tip.

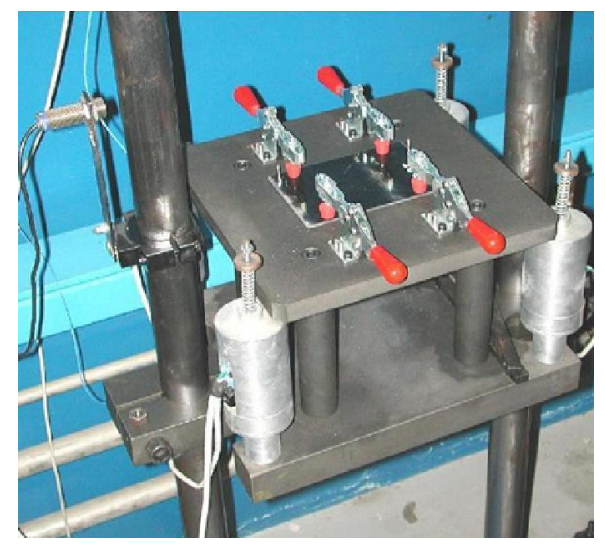

Fig. 3. Drop weight machine

\section{Results and discussion}

In this section the effect of PVDF nanofiber interleaved between GFRP layers on the impact characteristics, such as peak load $\left(\mathrm{P}_{\max }\right)$, contact duration $\left(\mathrm{t}_{0}\right)$, maximum deflection $\left(\mathrm{X}_{\max }\right)$, damage area and the absorbed energy are examined against the corresponding impact energy of 4.9J. The maximum load is the maximum contact force between the impactor and the composite in an impact event. The contact duration is the total contact time between the impactor and the composite specimen in a non-perforated case or up to the perforation instant in a perforated case. The maximum deflection is defined as the largest distance between the top surface of the composite specimen that has deflected and its initial position. The absorbed energy is the energy absorbed by the composite specimen in consequence of the formation of damage and the friction between impactor and specimens. These characteristics are important for understanding the impact response of composites. Fig. 4 represents impact force versus time and displacement (U) for plain and interleaved GFRP test specimens for the two different thicknesses of nanofiber mats. As shown the rising part of the curves are not smooth that because of the initiation and growth of damage.
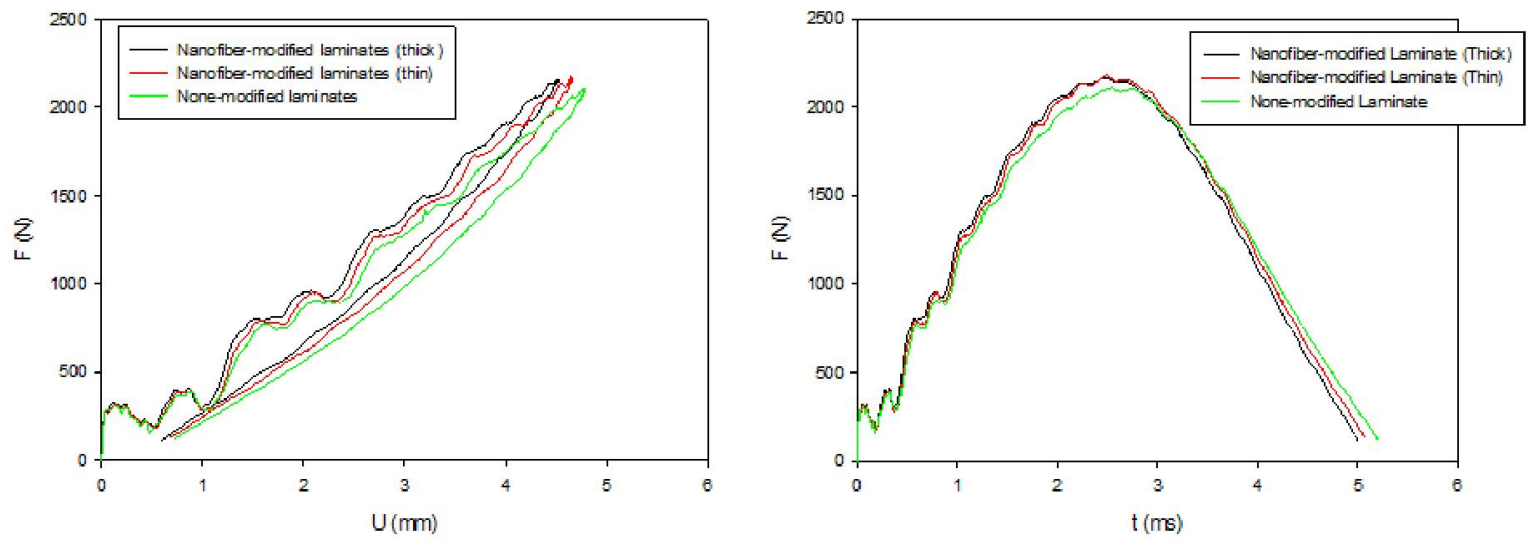

Fig. 4. Impact response of plain and interleaved GFRP laminates: A) Force vs. Displacement

B) Force vs. time duration of impact 
A glance on figures show that interleaved PVDF nanofiber does not affect on the curves. Although according to Fig. 4A the maximum displacement decreased by increasing the thickness of mats, this change is negligible. The details of impact response of GFRP laminates for both of interleaved laminates are presented in Table 2. Maximum effect belongs to absorbed energy which thin and thick nanofiber mats could increased $9.5 \%$ and $13.4 \%$, respectively. This information confirms that PVDF nanofiber is not a very good choice for toughening glass/epoxy laminates. Fig. 5 illustrates the SEM pictures of fractured surface of PVDF-modified laminate. As seen the nanofibers are visible which is because the curing temperature is less than the melt point of PVDF. These nanofibers can make links between adjacent layers (bridging) (palazzetti et al., 2013), but anyway this mechanism is not strong enough to improve impact response of the GFRP laminate.

Table 2. Impact parameters for plain and interleaved specimens

\begin{tabular}{lcccccc}
\hline & $\begin{array}{c}\mathrm{H} \\
(\mathrm{m})\end{array}$ & $\begin{array}{c}\mathrm{T} \\
(\mathrm{mm})\end{array}$ & $\begin{array}{c}\text { Absorbed } \\
\text { Energy }(\mathrm{J})\end{array}$ & $\begin{array}{c}\mathrm{P}_{\max } \\
(\mathrm{KN})\end{array}$ & $\begin{array}{c}\mathrm{U}_{\max } \\
(\mathrm{mm})\end{array}$ & $\begin{array}{c}\mathrm{t}_{0} \\
(\mathrm{~ms})\end{array}$ \\
\hline Plain specimen & 0.41 & 2.53 & 1.068 & 2102 & 4.78 & 5.2 \\
Interleaved specimen (Thin nanofiber) & 0.41 & 2.56 & 0.966 & 2176 & 4.66 & 5.07 \\
Variation (\%) & -- & 1.2 & 9.5 & 3.5 & 2.5 & 2.5 \\
Interleaved specimen (Thick nanofiber) & 0.41 & 2.66 & 0.925 & 2166 & 4.51 & 5.00 \\
Variation (\%) & -- & 5.1 & 13.4 & 3 & 5.6 & 3.8 \\
\hline
\end{tabular}

A)

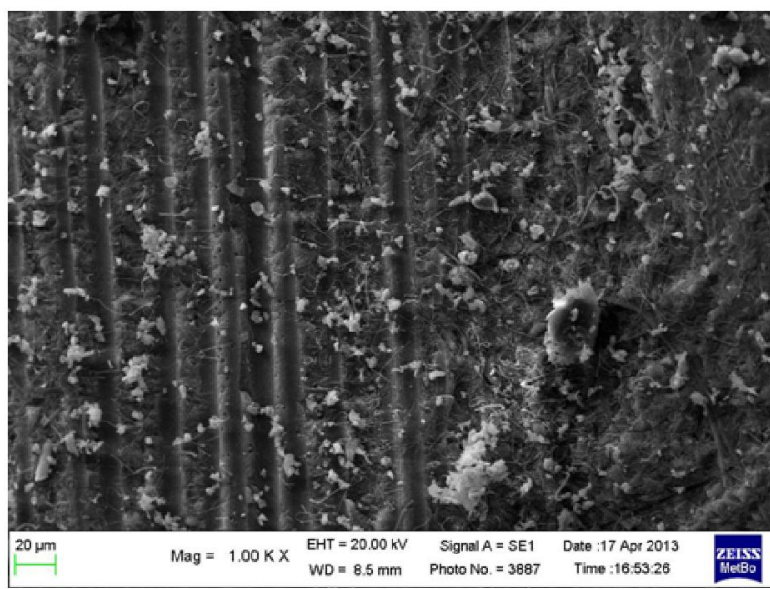

B)

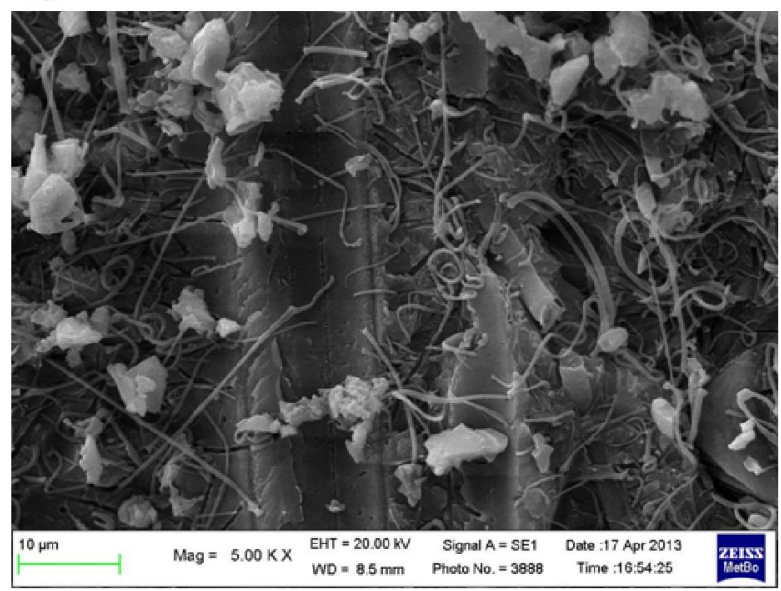

Fig. 5. SEM pictures of fracture surface of modified laminates in two magnifications

\section{Conclusion}

Plain and PVDF-interleaved GFRP laminates were tested under impact loading for considering the effect of PVDF nanofibers on the impact response such as damage resistance, maximum force, absorbed energy, and etc. The following results can be concluded from the fracture tests:

1- Effect of PVDF on the force-displacement curves is almost negligible.

2- Among the impact parameters, PVDF affects more on absorbed energy. This parameter increased 9.5 and $13.4 \%$ using thin and thick nanofibrous mats, respectively.

3- Curing temperature was less than melt point of PVDF, therefore nanofibers were existence between composite layers. This phenomenon lead to "bridging" mechanism during failure. 


\section{References}

Akangah P., Lingaiah S., \& Shivakumar K. (2010). Effect of Nylon-66 nanofiber interleaving on impact damage resistance of epoxy/carbon fiber composite laminates. Composite Structures, 92, 1432-1439.

Dow, M.B., \& Dexter H.B. (1997). Development of Stitched, Braided and Woven Composite Structures in the ACT Program and at Langley Research Center (1985 to 1997) Summary and Bibliography. Technical report.

Dransfield, K.A., Jain, L.K., \& Mai, Y.W. (1998). On the effects of stitching in CFRPs-I. Mode I delamination toughness. Composite Science and Technology, 59, 815-827.

Dzenis, Y.A.,\& Reneker D.H. (2001). Delamination resistant composites prepared by small diameter fiber reinforcement at ply interfaces. United States Patent 6265333.

Howard, W.E., Gossard, T., \& Robert, M.J. (1986). Reinforcement of composite laminate free edges with U-Shaped caps. In AIAA Paper, 1.

Ishai, O., Banks-Sills, L., \& Sela, N. (1978). The effect of adhesive thickness on interlaminar fracture toughness of interleaved CFRP specimens. Composites, 20, 257-264.

Jain, L.K., Dransfield, K.A., Mai, Y.W. (1998). On the effects of stitching in CFRPs-II. Mode II delamination toughness. Composite Science and Technology, 59, 829-837.

Li, G., Li, P., Yu, Y., Jia, X., Zhang, S., Yang, X., \& Ryu, S. (2008). Novel carbon fiber/epoxy composite toughened by electrospun polysulfone nanofibers. Materials Letters, 62, 511-514.

Lu, W.H., Liao, F.S., Su, A.C., Kao, P.W.,\& Hsu, T.J. (1995). Effect of interleaving on the impact response of a unidirectional carbon/epoxy composite. Composites, 26, 215-222.

Palazzetti, R., Zucchelli, A.,\& Trendafilova I. (2013). The self-reinforcing effect of Nylon 6,6 nanofibres on CFRP composite laminates subjected to low velocity impact. Composite Structures, 106, 661-671.

Sohn, M.S., Hu, X.Z., Kim, J.K.,\& Walker, L. (2000). Impact damage characterization of carbon fiber/epoxy composites with multi-layer reinforcement. Composites: Part B, 31, 681-691.

Verrey, J., Winkler, Y., Michaud, V.,\& Manson, J-AE. (2005). Interlaminar fracture toughness improvement in composites with hyper branched polymer modified resin. Composite Science and Technology, 65, 1527-1536. 